\title{
K12 Practitioners' Perceptions of Learning from Failure, Creativity, and Systems Thinking: a Collective Case Study
}

\author{
T. Logan Arrington ${ }^{1}$ (D) Alison L. Moore ${ }^{2} \cdot$ Lauren M. Bagdy $^{3}$
}

Accepted: 25 February 2021 / Published online: 6 March 2021

(C) Association for Educational Communications \& Technology 2021

\begin{abstract}
This article presents the results of a collective case study exploring how K12 practitioners perceive the interaction of systems thinking, creativity, and learning from failure within their professional practice. In order to identify K12 practitioners who were well-versed in systems thinking, we targeted students within an instructional design and technology graduate program that included a course on human performance improvement (HPI). At the conclusion of the semester, all students in the course were invited to participate in an individual, semi-structured interview where they discussed the relationship among these three concepts within their professional practice. Participants described how learning from failure and creativity manifest within their practice and through systems thinking. Additionally, they identified that learning from failure and creativity are crucial components of problem solving. Further insights for how these three concepts can impact professional practice are addressed.
\end{abstract}

Keywords Systems thinking $\cdot$ Learning from failure $\cdot$ Creativity $\cdot$ Collective case study $\cdot$ K 12 teachers $\cdot$ K 12 practitioners

Ackoff (2006) lauded the benefits of learning from mistakes within any organization. Not only are professionals able to make corrections and improvements by analyzing their mistakes, but additional opportunities for future success can be identified through critical reflection of the errors. Creativity plays a large role in this last step as it facilitates individuals' generation of potential ideas and solutions (Furnham and Nederstrom 2010). According to Ackoff (2006), for organizational leaders to identify successful next steps, high-level decisions must be made through the lens of the system. All three of these concepts - learning from failure, creativity, and systems thinking - are sought after in a variety of professions. In fact, employers repeatedly identify creativity and innovation, as well as critical thinking and problem solving, as skills they value and desire in employees (American Management

T. Logan Arrington logana@westga.edu

1 Department of Educational Technology and Foundations, College of Education, University of West Georgia, Carrollton, GA 30118, USA

2 Department of Educational Studies, College of Education, University of South Carolina, Columbia, SC 29208, USA

3 Department of Educational Psychology and Learning Systems, College of Education, Florida State University, Tallahassee, FL 32306, USA
Association 2012; Hart Research Associates 2013; IBM Institute for Business Value 2016). Overall, we argue that these three concepts are not only related, but support and build on each other exponentially. A key aspect of this relationship among systems thinking, creativity, and failure is their interconnection. Building dexterity in one of these skills could better position an individual to engage in and improve the other two. For example, as one begins to cultivate a mindset that is conducive to failure experiences, they could potentially begin exploring failures in a more holistic manner, noting the contributing factors that led to it (i.e., systems thinking) while simultaneously exploring innovative methods for overcoming these instances (i.e., creativity). Novices may have a hard time recognizing this potential development, which is why support in a variety of forms (e.g., instruction, mentoring, feedback, etc.) is beneficial.

This study aims to investigate how K12 practitioners perceive the interaction of these three concepts within their professional practice. At each level within a K12 organization, practitioners should balance the needs of various systems and subsystems, as well as work within and recognize the constraints of these systems. While they may do this instinctively (or not at all), they may not recognize the bigger picture or see the system as a whole. Additionally, K12 practitioners should ideally exercise and model the remaining concepts of creativity and learning from failure. Teachers should demonstrate 
their creativity through their own instructional process and provide an environment that nurtures it as students creatively explore. In terms of failure, teachers should create an environment that supports students through the learning process by using mistakes and struggles as opportunities to improve, while also utilizing the same mindset in their own practice. Thus, this study explored how K12 practitioners, who were recently exposed to systems thinking, made changes or intended to make changes to their professional practice regarding learning from failure and creativity.

\section{Literature Review}

\section{Learning from Failure}

Within the learning process, failure can be conceptualized in a variety of ways. In seminal works in the field of education, failure has been conceptualized as deficiencies for learners to recognize, using a variety of formats (e.g., direct instruction, feedback, trial and error, etc.), in order to improve their own performance (Ericsson et al. 1993; Zimmerman 1990). The idea of failure is also addressed in growth mindset (Dweck 2016). When considering a growth mindset, struggles and failures are seen as a natural occurrence that is part of the learning process. The emphasis is more on long-term outcomes than initial effects. Depending on some circumstances, failure can actually be motivating and provide students with the motivation to work harder in the following instances. Through reinforcement of high effort as students encountered failure, students may be reinforced tangentially and feel more motivated to put in similar levels of effort in the future (Eisenberger 1992). Recently, numerous authors in the field have indicated that strategically designing failure experiences within the learning process to force learners to encounter failure is beneficial (Tawfik et al. 2015; Kapur 2008). These types of strategies have been found to be more effective than those where learners do not encounter designed failure experiences (Darabi et al. 2018).

Perhaps one of the most discussed frameworks for considering failure in the learning process in recent years is the concept of productive failure (Kapur 2008, 2016). Productive failure simply is a situation in which learners fail in their initial or short-term performance, but through this failure gain more meaningful long-term learning. One common approach for eliciting productive failure is through problem solving prior to instruction (Kapur 2016; Manolo and Kapur 2018). This approach has proved to be more effective in terms of conceptual knowledge gains when compared to other instructional strategies (see Kapur 2008, 2009, 2011, 2013, 2014; Kapur and Kinzer 2009; Loibl and Rummel 2014a, 2014b; Westermann and Rummel 2012). There are other aspects at play as learners work through their problem solving. For example, Ziegler and Kapur (2018) found that encouraging students to be creative led to more solutions (i.e., failures); however, it also led to greater long-term gains as it required learners to have a deeper understanding of the conceptual features of the problem as well as the problem space. It is no surprise that when learners exercise their creativity, they can respond to failure in a more productive way.

\section{Creativity}

Creativity has been described as a complex cognitive process (Randle and Stroink 2018) that yields "both novel and useful ideas, concepts or products" (Furnham and Nederstrom 2010, p. 957). The ability to identify and construct new options requires an agile mind, and creative thought is unique in that it demonstrates flexibility, originality, and utility (Furnham and Nederstrom 2010; Lai et al. 2018). Both an individual and organizational trait (Andriopoulos 2001), a creative mindset may lead to the generation of innovative avenues for problem solving. Additionally, when considered as a skill on a continuum, creativity may be developed in learners through targeted, direct instruction (Zhou et al. 2014; Lai et al. 2018). Within direct instruction, well- designed opportunities for practice may allow individuals to engage in and increase their creative thinking abilities.

Across settings and disciplines, creativity has been explored as a means of responding to failure and solving problems. For example, Sawyer (2019) investigated how instructors positioned art students to confront failure in an effort to promote their creativity. By assigning intentionally vague projects, art instructors provided students with an opportunity to apply and hone their unique creative thinking skills. Frustration, failure, and feedback were integral elements of instruction that promoted student creativity (Sawyer 2019). Similarly, Ziegler and Kapur (2018) looked at the role of creativity as students learn algebra. They argued that effective mathematics instruction should develop both algebraic and creativity skills concurrently. Additionally, the researchers highlighted how student mistakes and creative problem solving went hand-in-hand. Through these examples, it can be seen how viewing episodes of struggle and failure through a creative perspective can drive individuals to consider new possibilities for improvement, as well as increase their creativity directly. The task of observing and internalizing a complex, challenging situation, and subsequently producing a range of potential ideas and solutions, clearly lends itself to benefitting from systems thinking.

\section{Systems Thinking}

Systems thinking is an approach to viewing complex systems as a whole rather than isolating and focusing on their individual components (Arnold and Wade 2015). Ackoff (2006) 
called for all organizational leaders to engage in systems thinking to guide their decision-making process. In this regard, a connection clearly emerges between systems thinking and human performance. Human performance improvement (HPI) is "the science and art of improving people, process, performance, organizations, and ultimately society" (Van Tiem et al. 2012, p. 5), and systems thinking is at the heart of HPI.

For our approach, systems thinking is considered as the ability to recognize the interacting components that exist within an organization (Ackoff 1999; Ghrajedaghi 1999). To holistically address these performance problems, practitioners should have a thorough understanding of the organization and environments within which the problems are occurring as systems with various interacting components. Thus, practitioners must consider multiple perspectives from the various roles within the environment (e.g., students, teachers, administrators). Further, they must also expand their problem-solving perspectives to recognize the variety of solutions available to them. It is no surprise that various researchers consider systems thinking a crucial part of critical thinking (Ventura et al. 2017). Based on the characteristics identified in their systemic analysis of the environment and organization, practitioners pick the most appropriate solutions.

Ackoff (2006) highlighted the importance of engaging in systems thinking while learning from failure. Within the context of an organization, failure should be considered systemically to best respond to that failure. Failure can be treated as a catalyst for improvement and investigated in a way that considers all of its contributing factors. The connection between learning from failure and creativity has been documented in cases where learners are tasked with generating multiple solutions to a problem (Kapur 2008, 2016) or generating problems themselves (Ziegler and Kapur 2018). Randle and Stroink (2018) made the connection between systems thinking and creativity, in that systems thinking, as a cognitive process that calls for flexible, holistic perspectives, is associated with heightened creativity. We argue that these three concepts are interconnected and strengthen each other during real-world problem solving. We also posit that systems thinking is a skill that augments both of these concepts, learning from failure and creativity. Practitioners across disciplines can benefit by thinking systemically, and this equally true for K12 practitioners. There are a variety of ways that systems thinking can be applied to K12 practitioners and the accomplishment of their jobs (Betts 1992).

The purpose of this study was to explore how K12 practitioners make meaning of these three concepts - learning from failure, creativity, and systems thinking - through their professional practice. Our study was guided by the following question: How do K12 practitioners who recently completed a graduate HPI course perceive learning from failure and creativity within their professional practice when considering these concepts through a systems thinking lens?

\section{Methodology}

\section{Design}

To explore K12 practitioners' perceptions of these two concepts through a systems perspective, we employed a collective case study design. Collective case study design was most appropriate for our research because we interviewed several practitioners who were not colocated to examine our phenomena (Stake 2000). In order to identify K12 practitioners who were versed in systems thinking, we targeted students within an instructional design and technology graduate program that included a course on HPI.

\section{Case Context}

Those invited to participate in this study had all previously completed a graduate course on HPI. This course is offered in an educational specialist degree program in instructional technology at a regional comprehensive university in the southeastern United States. The purpose of this course is to introduce students to the field of HPI, specifically focusing on how to engage in the full HPI process by conducting a performance systems analysis. At the same time, students learn about systems thinking and must apply it throughout the entire HPI process. An additional goal of the course is to cultivate students' critical thinking skills. Human performance improvement has been used in the past as a framework for teaching critical thinking skills (Darabi and Arrington 2017). The application of the HPI model requires analysis, synthesis, evaluation, and communication. An objective, systemic, and systematic approach is necessary for an accurate examination of a performance problem and its context, as well as for identification of appropriate interventions to remedy the issue.

Within the course, students collaboratively work through the steps of a performance systems analysis, explore various non-instructional interventions that are used in HPI, and examine the experiences of others through analysis of case studies. Predominantly, the course is taken by K12 practitioners, since individuals in these careers comprise the majority of students in the program. These practitioners serve in a variety of K12 roles, such as classroom teachers, administrators, instructional coaches, and school librarians. However, the course is designed to emphasize the transferability of HPI and associated skills across contexts and disciplines.

The course is a technology-enhanced course (i.e., fully online with optional synchronous meetings that integrate various technological tools). Additionally, the course is implemented with a co-teaching model. Co-teaching is the systematic planning, delivery, and evaluation of a course by two or more instructors where each instructor is treated equally (Chanmugam and Gerlach 2013). We selected this course for the study because two of us currently serve as instructors 
of record. The course spans five modules that focus on the overarching HPI model. Within each module, students complete assignments that together create a semester-long realworld project. These assignments include:

- An identified performance problem;

- A data collection plan to address said problem;

- An environmental, gap, and cause analysis based on data collected from the plan; and

- Recommendations that directly address the identified causes and potential barriers.

\section{Participants}

Using a purposeful sample, we recruited former students of this class. We did not contact potential participants until after they completed the course, and there was no incentive to participate. Specifically, we invited all students who completed the course in the Fall 2019, Spring 2020, and Summer 2020 semesters to participate in the study. Seventeen former students volunteered to be interviewed. From those 17, ten interviews were conducted as some individuals did not respond to requests for interviews. The ten participants were all K12 practitioners in a southeastern state in the United States. Five of the participants were classroom teachers, two at the high school level and three at the middle school level. The remaining five participants held a variety of leadership roles within K12 schools and districts (e.g., principals, school library media specialists, district-level coaches). On average, the participants had 11 years of experience in K12. Of our ten participants, only two were in the same school district (i.e., Participant 1 and Participant 4); however, they held different roles. Detailed information about each participant is included below in Table 1.

\section{Data Collection}

The 17 participants who volunteered to be interviewed completed a brief survey. The survey included one force-response question, "Has HPI impacted your professional practice?" They were also offered the option to explain their answer further. This question was not exclusionary, and all participants were eligible to participate in the study. Additionally, the participants granted their consent to participate in the interviews. When interviewed, the participants provided their verbal consent again to the interview being recorded. In pairs, we conducted virtual semi-structured interviews with the participants through Zoom. Specifically, we asked about their definitions of learning from failure and creativity, as well as the impact of systems thinking on those two concepts within the frame of their professional practice. Example questions and sub-questions included:

- Has learning about systems thinking changed the way you address or will address "failure" in your professional practice?

- Has systems thinking impacted (or do you anticipate it impacting) how you interact with students or employees in regard to learning from failure?

- Has learning about systems thinking changed the way you think or will think "creatively" in your professional practice?

- Has it impacted (or do you anticipate it impacting) how you interact with colleagues in regards to creativity?

- Do you see a relationship between these three concepts (learning from failure, creativity, and systems thinking)?

Upon completion of the interviews, the audio recordings were uploaded into an auto transcription service (otter.ai).

Table 1 Participants' information

\begin{tabular}{lll}
\hline Participant ID & Current Position & Years of K12 Experience \\
\hline 1 & High School Science Teacher & 14 \\
2 & High School Science Teacher & 9 \\
3 & Elementary School Library Media Specialist & 15 \\
4 & Elementary Principal & 12 \\
5 & District-Level Content Specialist & 10 \\
6 & District-Level EdTech Specialist & 4 \\
7 & District-Level Coordinator & 14 \\
8 & Middle School Science Teacher & 12 \\
9 & Middle School English Teacher & 11 \\
10 & Middle School Science Teacher & 8 \\
\hline
\end{tabular}


Then, we reviewed the transcripts against the recordings to check for accuracy. Additionally, the transcripts were anonymized prior to data analysis.

\section{Data Analysis}

Data analysis focused on identifying how K12 practitioners perceive learning from failure and creativity through a systems thinking lens. We began the data analysis process by reading through transcripts to familiarize ourselves with the raw data. Implementing descriptive coding, we generated individual notes summarizing topics within transcript excerpts (Saldana 2013). We met to discuss the patterns, generating the first iteration of codes. We selected two interview transcripts to code independently using separate Google Docs and applied initial codes via the comments tool. After individually coding the two interview transcripts, we discussed the codes until we reached a consensus. At this stage, we had compiled a list of 35 codes across nine thematic groups.

In the next round of coding, we applied the revised set of codes and themes to the remaining interview transcripts. We divided the remaining eight interviews among the research team for individual analysis (two of us analyzed three transcripts, one of us analyzed two transcripts). We met again to compare our independent analyses. Some codes were restructured to more accurately capture participants' perceptions and experiences, and any codes and themes that went unused were removed to strengthen coding structure, resulting in 20 codes across six themes. The subsequent section will discuss our findings across the six themes.

\section{Findings}

\section{Describing Learning from Failure}

The K12 practitioners we interviewed were relatively consistent when describing learning from failure. All but one of the K12 practitioners described learning from failure as a positive experience, ultimately leading to an individual's growth. One of the teachers discussed that they actively promote learning from failure in their classroom. Participant 1, a high school science teacher, expressed that failure is part of the scientific process, so there is a natural space for it in their teaching and professional practice:

\footnotetext{
"In science, failure is not bad at all. It just means you can take something that you thought, or you predicted and... move on to the next solution or the next thought or hypothesis. So, it's actually a learning experience as opposed to a negative experience."
}

Participant 7, a district-level coordinator, described having prior teaching experience. They expressed that learning from failure is a "critical" part of the classroom experience because it helps students identify their mistakes and make future adjustments. However, Participant 7 expressed that failure is not accepted at their current school. Rather, it is reframed as something positive:
"We don't allow failure in my school. If they do not pass a test, they have to continue studying until they pass. And so, you know, we don't offer failing grades... Fail stands for first attempt in learning. So, I definitely al- ways feel like failure should be looked at as an oppor- tunity and not as something negative."

Not all of the K12 practitioners had positive feelings about failure and subsequently learning from failure. Participant 4 , an elementary school principal, described failure as a negative experience for students:
"I work with young kids... terms like failure in my book are not appropriate. And I try not to ever use them with the kids because learning is such a process and kids are at such varying levels... their abilities and where they're at is different."

\section{Describing Creativity}

Unlike learning from failure, the descriptions of creativity varied across the K12 practitioners. The most common description of creativity involved the phrase "thinking outside the box." Of the ten participants, four explicitly described creativity using this phrase. Additionally, four of the participants described creativity as a response to a problem or issue. Participant 6, the district-level EdTech specialist, stated that:

"[Creativity is] possible solutions for issues... taking what you have and seeing what you can make out of it."

The K12 practitioners also described creativity as adding a personal, unique touch, especially when delivering instruction. Participant 5, a district-level content specialist, described that:

"Creativity is really the thing that I like most about teaching; it's that adding 'you' into your content or into your lessons... the creativity piece is what allows the teachers to take the content and make it come alive."

\section{Description of the System in which they Operate}

There was also variation across the K12 practitioners regarding the systems in which they operate. While the five teachers 
we interviewed acknowledged that they are part of larger systems (e.g., school, district), they provided examples of systems primarily at the classroom level. They described each classroom as its own system within the greater system of the school. The other five K12 practitioners we interviewed served in administrative roles, situating their descriptions of systems at the school level and district level.

\section{Systems Thinking and Learning from Failure: Illuminating the Problem}

The K12 practitioners were asked to describe how systems thinking impacts how they address failure in their professional practice. Except for Participant 4, the elementary school principal who did not acknowledge failure within the K12 context, all K12 practitioners described that failure illuminates problems within a system. They provided examples of scenarios related to problem solving, using systems thinking to better understand the problem, and the environment. Participant 5, a district-level content specialist, discussed the issue of low performing schools not achieving state-mandated benchmarks. This participant and their colleagues used a systems thinking lens to identify the struggling groups and where interventions were necessary:

\begin{abstract}
"We're so focused on getting low performing schools to meet those benchmarks that the state's putting in front of us and trying to find out what is holding certain subgroups back from success... We often see that those same kids are struggling in all of the different subjects and it comes back to reading vocabulary acquisition."
\end{abstract}

Additionally, when describing how systems thinking impacts interactions with colleagues, Participant 1 , a high school science teacher, referenced the challenging experiences immediately following the initial remote learning policies in Spring 2020. Suddenly being required to transform existing face-toface lessons into virtual formats resulted in "a lot of people that feel like failures." During the transition to remote instruction, this participant identified veteran teachers, formerly confident in their in-person classrooms, as those most likely to struggle with unfamiliar technology. By teachers openly expressing that they felt like failures, Participant 1 and her school were able to identify an area of improvement regarding technology implementation.

\section{Systems Thinking and Creativity: Illuminating the Solution}

When asked to describe how systems thinking impacts how they address creativity in their professional practice, the K12 practitioners described that they use creativity to illuminate solutions to the problems within a system. After problems are identified within a particular system, creativity facilitates greater options for solutions. Participant 5, a district-level content specialist, explained that they continuously faced the problem of teachers not using classroom resources purchased for them at the district level. To address this problem, Participant 5 described using creative professional development activities to motivate the teachers to adopt these resources. Similarly, Participant 3, a library media specialist in an elementary school, also recognized systems thinking and creativity influencing the way they interact with teachers:

"I'm always trying to find ways to make collaboration easier for them... I almost want it to be seamless... [I spend time] looking at how I can use [and] integrate technology more with the media center."

In order to integrate beneficial support naturally into teachers' workdays, the library media specialist must understand the teachers' systems in order to brainstorm successful options. Also, technology served as a catalyst for further creative exploration and problem solving for the library media specialist. Additionally, the teachers we interviewed discussed using creativity as part of their teaching strategies, especially when introducing concepts that their students may view as either dull or challenging. Participant 6, the district-level EdTech specialist, had difficulty conceptualizing the relationship between systems thinking and creativity, describing them as two mutually exclusive concepts.

\section{Relationship between Learning from Failure, Creativity, and Systems Thinking}

At the end of their interview, the K12 practitioners were asked about the relationship between failure, creativity, and systems thinking. Participant 5 stated the relationship was a "braid."

"...Without one of the strands, and it's not going to be the prettiest braids. So if you've got all three, you've got all of the tools really needed to end up coming up with a solution to the problem."

Some of the participants described failure as the impetus, which prompted systems thinking. Participant 9, a middle school English teacher, stated:

"When you've failed at something, you try to figure out the problem... So you start thinking in a, in a systems thinking, you know, 'how can I improve my organization or my department.",

Other participants described systems thinking as the impetus, which resulted in identifying problems. Participant 4 , an elementary school principal, described: 
"Schools are complex systems and you're always going to be looking for ways to improve. There's no one size fits all program that's going to solve every problem that you have."

Regardless of the impetus described by the participants, creativity was described as the process for finding a solution to the problem.

\section{Discussion}

The practitioners involved in this study defined learning from failure, for the most part, in a way that is rooted in the existing literature. Whether working within or outside of a classroom, participants overwhelmingly described struggle and challenge as beneficial experiences that supported overall learning. Actively encouraging a positive, persistent perspective in students, and sometimes colleagues, when addressing episodes of failure, participants also cultivated key elements of growth mindset (Dweck 2016). Failure is an integral part of the learning process and not a terminal state; it is only a terminal state if those involved (i.e., teachers, administrators, and students) allow it to be. This is reminiscent of the participant who explained that failure was not a possible outcome at their institution due to the culture; established policies denied students from remaining in a terminal state of failure. Other participants, especially teachers, embraced failures in the classroom and maximized the positive opportunities that students' mistakes and errors presented. Failure has the potential to serve as a powerful learning and transformative agent, but only if all involved recognize and leverage the same qualities. Unsurprisingly, researchers have argued that in order to be conducive, the system needs to be built in such a way that allows for learners to navigate this struggle of failure (Hannigan 2018). There needs to be a system that is amenable to learning from failure in place for it to be extremely beneficial. These optimistic accounts of failure differ from the principal who shunned the idea of failure and described a school culture that refused to even use the term failure. This is a system that is not welcoming to the idea of failure. The mindset held by the leader of the school is one where failure is not even an option. One of the biggest concerns that accompany any learning from failure strategies is the stigma that is attached to the word. Often, failure is a shocking turn and the reaction of this leader is not an isolated incident.

In regard to creativity, however, participants demonstrated a more consistent conceptualization. A strong consensus among participants found that creativity represented the means to solve problems by "thinking outside the box." This flexible thinking process leads to brainstorming new options that are successful or designing a solution that previously did not exist. The connection between creativity and problem solving is well established (Lai et al. 2018) and, as one of the $4 \mathrm{Cs}$ that are fundamental competencies for twenty-first Century Learners, creativity is essential for success in personal and professional life (Battelle for Kids 2019).

When prompted with questions about systems thinking and their professional practice, participants were able to describe their immediate system (and sub- and supersystems). Teachers spoke intimately about their departments, grades, classrooms, and student groups, whereas administrators and coordinators tended to describe their districts, schools, and committees. Across these similar on-the-spot demonstrations of systems thinking, an interesting pattern emerged. Although teachers seemed to possess the same mastery of systems thinking as administrators, albeit at different levels within their respective systems, their explanations were more descriptive and lacked action. This contrasted with administrators' interviews, which involved anecdotes of authority and potential decisions. Such a difference may be indicative of the control each group has within their institutions. Hmelo-Silver and Pfeffer (2004) found that, based upon their purpose for being within a system, participants possessed different mental models. This could potentially explain the difference between the perspectives of teachers and administrators as they have different purposes within the system. Additionally, most of the work on systems thinking typically focuses on those decision makers (e.g., managers) and ensuring that they are equipped to use it when they make decisions (Ackoff 2006). Although all participants engaged in systems thinking, teachers may not perceive themselves as wielding enough power to enact change, whereas administrators are capable of decision making. However, with that being said, teachers' knowledge of system thinking still granted them some form of agency in their organizations.

Participants identified a consistent relationship between these three concepts. The interesting distinction between participants was with the impetus of the interaction. Some saw systems thinking as the first step (i.e., they use systems thinking to identify and locate failures), while others indicated that failure was the driving force (i.e., a failure occurs and then they look at said failure systemically). Regardless, the connection between system thinking and learning from failure is noted deeply in problem solving. The response, whether it is a failure identified through systems thinking or the use of systems thinking in response to a failure, these practitioners are engaging in problem solving. Systems thinking is aligned to critical thinking as an important approach to solving problems (Ventura et al. 2017). Additionally, systems thinking allows these practitioners to see things in a more holistic light. K12 practitioners, teachers especially, are tasked with using data to make a variety of decisions (Kaufman et al. 2014). This data is usually focused on the classroom level in a variety of different formats (Schifter et al. 2014). Through systems thinking, practitioners can consider data that is impactful within and outside 
of their sphere of influence. Enabled by a systems perspective, they will look at problems with a more holistic understanding of the performers and the environment to be better prepared to address these concerns.

As mentioned previously, systems thinking and creativity share many similarities as complex cognitive processes. Both require high-level, comprehensive perspectives of situations, and both yield useful results tailored to a specific context. Out of the ten practitioners, nine explained that creativity was the conduit for selecting potential solutions to problems within a system. While our participants were not novice thinkers, many of them were new to systems thinking. Through considering it and the relationship between creativity, they demonstrated some of the low-level connections (e.g., connecting it to the process of selecting an intervention) rather than seeing a broader picture. As these participants explore and practice these concepts in conjunction with one another, their perspective should expand (Persky and Robinson 2017). Although most participants described creativity as an independent exercise that occurs while considering the larger system as you select an intervention, we see these as parallel activities that complement each other. In order to visualize and construct a system, with its multifaceted components and sometimes hidden relationships, one must be flexible and agile in thinking through the system's various connections and levels. Creativity facilitates this exercise, in that creative thought augments what is already known with new, original ideas, thus fleshing out a system's finer details and interconnections. Likewise, when applying creativity to solve a problem, systems thinking may expedite the process. With its focus on holistic views, systems thinking positions one to take into account all components and consider the whole playing field. This birds-eye view of a problem, as well as the system in which it exists, makes it possible for individuals to identify solutions that may not have been tried before. Engaging in both systems and creative thinking allows individuals to maximize all system components and arrive at elegant, effective answers. Again, although participants did not explicitly communicate this robust of a connection, we see this connection and believe that evidence from their interviews suggests that there is more at hand than what they may directly acknowledge.

Pervasive throughout these interactions is the use of technology. A teacher introduces new vocabulary words to her fourth graders via an interactive whiteboard, a media specialist introduces a new app to a veteran chemistry teacher, and a principal welcomes other district leaders to a virtual roundtable to discuss budgetary issues. Technology is pervasive in the professional lives and responsibilities of K12 practitioners, regardless of their specific roles. This role is even greater given the current state of K12 education due to COVID-19. Considering the interaction described between technological, pedagogical, and content knowledge (TPACK), strengths or deficits in technological knowledge can impact the overall actions of professional practice (Koehler and Mishra 2009). While TPACK is referencing instructional practice, an item that not all K12 practitioners engage in daily, it still is applicable to overarching duties in K12 as leadership. As such, and as suggested by interviews, technology plays dual roles within this context - it is both failure and solution, and we see technology as manifesting in a cycle. It may present practitioners with a glitch (i.e., a broken link or a non-functional Chromebook) that obstructs their progress and work. Just as likely, technology may also offer practitioners a way to overcome an existing problem (i.e., an automated macro to save time or a virtual conference call to facilitate immediate communication). Then, just as quickly again, the technology may malfunction, exposing another failure, until another form of technology emerges as the solution. Throughout this cycle, practitioners are experiencing problems and failure, thinking systemically and creatively as they search for solutions, and gaining expertise in highly valuable skills. Within Table 2 below, we have provided the main takeaways from the findings of this study.

\section{Limitations and Future Research}

We identified limitations of this study, as well as several avenues for future research. First, this project occurred while K12 practitioners were still responding to the COVID-19 crisis. Participants were actively implementing and troubleshooting emergency procedures for delivering instructional lessons and support to student families throughout data collection. That being the case, interviews often included stories pertaining to individuals' and schools' reactions to COVID19. Had this study been conducted outside of this unique timeframe, example anecdotes and comments from participants may have yielded different patterns, thus justifying additional investigation in the future.

Second, several characteristics of the ten participants may have influenced the findings of this study. Since we recruited former students of an HPI graduate-level course that directly introduced systems thinking, future studies could pursue practitioners who have not been formally exposed to the concept. This may be beneficial since participants mentioned that, while they had been engaging in systems thinking for years within their professional practice, only recently had they learned its official name. Additionally, participants were all mid- to late-career professionals. Even the most novice participant of this study, who possessed four years of experience in $\mathrm{K} 12$, had years of previous experience prior to a career transition. This being the case, an investigation into the perceptions of early career practitioners deserves attention due to the nature of workplace learning. 
Table 2 Summary of findings and main takeaways

\begin{tabular}{|c|c|}
\hline Findings & Main Takeaways \\
\hline $\begin{array}{l}\text { Participants recognized failure as a natural part of the learning } \\
\text { process. }\end{array}$ & Failure (i.e., of students, colleagues, and self) can be framed as an opportunity to learn. \\
\hline $\begin{array}{l}\text { Participants saw creativity helping their problem-solving } \\
\text { efforts. }\end{array}$ & Solutions to problems can be brainstormed by "thinking outside the box." \\
\hline $\begin{array}{l}\text { Participants' locations within their systems influenced their } \\
\text { descriptions of the systems. }\end{array}$ & $\begin{array}{l}\text { A system should be viewed as an entity in its entirety rather than solely from one } \\
\text { viewpoint. }\end{array}$ \\
\hline $\begin{array}{l}\text { Participants identified a relationship between failure, } \\
\text { creativity, and systems thinking. }\end{array}$ & $\begin{array}{l}\text { Individuals should practice responding to failures, thinking creatively, and engaging in } \\
\text { systems thinking to solve problems with promising, innovative solutions. }\end{array}$ \\
\hline $\begin{array}{l}\text { Technology was both a catalyst of challenges (i.e., failures) } \\
\text { and a solution to problems (i.e., creativity). }\end{array}$ & $\begin{array}{l}\text { Technology should be thoughtfully integrated as unsuccessful implementation can lead } \\
\text { to systemic issues. }\end{array}$ \\
\hline
\end{tabular}

Furthermore, many participants held current roles in public K12 settings, and also possessed a background in Science (e.g., current or former role), both of which may have impacted their perceptions of the studied concepts. Professional exposure to the scientific method, research process, and experimentation may have facilitated their understanding and application of learning from failure, creativity, and systems thinking. However, with pressure from public system constraints to meet external goals and standards, which are often tied to state and federal funding, public K12 practitioners may not be free to take advantage of the long-term benefits that struggle and failure offer learners. Future studies may explore whether K12 teachers from public school systems, as opposed to their private school colleagues, in fact feel more hindered from leveraging learning from failure and facilitating growth mindset in their classrooms. Additionally, targeting K12 practitioners without such strong science backgrounds may reveal different accounts in terms of familiarity and acceptance of failure as a beneficial strategy.

Lastly, while the current study conducted individual interviews with participants that revealed valuable perceptions, future researchers should consider designing a deeper exploration into the individuals and their perceptions of these complex topics. Combining methods, such as observations and a series of interviews over time, would allow for a more comprehensive and fuller picture to emerge (Read 2018). Data collected throughout an extended period of time, rather than during one conversation, would strengthen findings and provide a more in-depth understanding of the phenomenon.

\section{Declarations}

Research Involving Human Participants The study, including all recruitment and data collection procedures, was approved by the Institutional Review Board at the University of West Georgia - IRB \#: UWG 2020 0191.

Informed Consent Informed consent was obtained from all individual participants included in the study.
Conflict of Interest The authors have no conflicts of interest to declare that are relevant to the content of this article.

\section{References}

Ackoff, R. L. (1999). Ackoff's best: His classic writing on management. Hoboken: Wiley.

Ackoff, R. L. (2006). Why few organizations adopt systems thinking. Systems Research \& Behavioral Science, 23, 705-708. https://doi. org/10.1002/sres.791.

American Management Association (2012). Critical skills survey. American Management Association. https://www.amanet.org/ assets/1/6/2012-critical-skills-survey.pdf. Accessed 19 Nov 2020.

Andriopoulos, C. (2001). Determinants of organisational creativity: A literature review. Management Decision, 39(10), 834-841. https:// doi.org/10.1108/00251740110402328.

Arnold, R. D., \& Wade, J. P. (2015). A definition of systems thinking: A systems approach. Procedia Computer Science, 44, 669-678. https://doi.org/10.1016/j.procs.2015.03.050.

Battelle for Kids (2019). Framework for 21st Century Learning Definitions. http://static.battelleforkids.org/documents/p21/P21 Framework_DefinitionsBFK.pdf. Accessed 19 Nov 2020.

Betts, F. (1992). How systems thinking applies to education. Educational Leadership, 50(3), 38-41.

Chanmugam, A., \& Gerlach, B. (2013). A co-teaching model for developing future educators' teaching effectiveness. International Journal of Teaching \& Learning in Higher Education, 25(1), 110 117.

Darabi, A., \& Arrington, T. L. (2017). Designing instruction for critical thinking in a graduate course on evaluation of training. International Journal of Teaching and Learning in Higher Education, 29(3), 1-9.

Darabi, A., Arrington, T. L., \& Sayilir, E. (2018). Learning from failure: A meta-analysis of the empirical studies. Educational Technology Research and Development, 66(5), 1101-1118. https://doi.org/10. 1007/s11423-018-9579-9.

Dweck, C. (2016). Mindset: The new psychology of success. New York: Penguin Random House.

Eisenberger, R. (1992). Learned industriousness. Psychological Review, 99(2), 248-267.

Ericsson, K. A., Krampe, R. T., \& Tesch-Römer, C. (1993). The role of deliberate practice in the acquisition of expert performance. Psychological Review, 100(3), 363-406. https://doi.org/10.1037/ 0033-295x.100.3.363.

Furnham, A., \& Nederstrom, M. (2010). Ability, demographic and personality predictors of creativity. Personality \& Individual 
Differences, 48(8), 957-961. https://doi.org/10.1016/j.paid.2010. 02.030 .

Ghrajedaghi, J. (1999). Systems thinking: Managing chaos and complexity. Butterworth-Heinemann.

Hannigan, S. (2018). A theoretical and practice-informed reflection on the value of failure in art. Thinking Skills and Creativity, 30, 171179. https://doi.org/10.1016/j.tsc.2018.02.012.

Hart Research Associates. (2013). It takes more than a major: Employer priorities for college learning and student success. http://www.aacu. org/leap/documents/2013_EmployerSurvey.pdf. Accessed 19 Nov 2020.

Hmelo-Silver, C. E., \& Pfeffer, M. G. (2004). Comparing expert and novice understanding of a complex system from the perspective of structures, behaviors, and functions. Cognitive Science, 28(1), 127138.

IBM Institute for Business Value. (2016). Redefining boundaries: Insights from the global C-suite study. https://www.ibm.com/ downloads/cas/VJEP6Z9D. Accessed 19 Nov 2020

Kapur, M. (2008). Productive failure. Cognition \& Instruction, 26(3), 379-424. https://doi.org/10.1111/cogs.12107.

Kapur, M. (2009). Productive failure in mathematical problem solving. Instructional Science, 38(6), 523-550. https://doi.org/10.1007/ s11251-009-9093-x.

Kapur, M. (2011). A further study of productive failure in mathematical problem solving: Unpacking the design components. Instructional Science, 39(4), 561-579.

Kapur, M. (2013). Comparing learning from productive failure and vicarious failure. Journal of the Learning Sciences, 23(4), 651-677. https://doi.org/10.1080/10508406.2013.819000.

Kapur, M. (2014). Productive failure in learning math. Cognitive Science, 38, 1008-1022. https://doi.org/10.1111/cogs.12107.

Kapur, M. (2016). Examining productive failure, productive success, unproductive failure, and unproductive success in learning. Educational Psychologist, 51(2), 289-299. https://doi.org/10.1080/ 00461520.2016 .1155457$.

Kapur, M., \& Kinzer, C. K. (2009). Productive failure in CSCL groups. International Journal of Computer-Supported Collaborative Learning, 4(1), 21-46. https://doi.org/10.1007/s11412-008-9059-z.

Kaufman, T. E., Graham, C. R., Picciano, A. G., Popham, J. A., \& Wiley, D. (2014). Data-driven decision making in the K-12 classroom. In Handbook of research on educational communications and technology (pp. 337-346). New York, NY: Springer.

Koehler, M., \& Mishra, P. (2009). What is technological pedagogical content knowledge (TPACK)? Contemporary Issues in Technology and Teacher Education, 9(1), 60-70.

Lai, E. R., Yarbro, J., DiCerbo, K., \& de Geest, E. (2018). Skills for today: What we know about teaching and assessing creativity. London: Pearson.

Loibl, K., \& Rummel, N. (2014a). The impact of guidance during problem-solving prior to instruction on students' inventions and learning outcomes. Instructional Science, 42(3), 305-326. https:// doi.org/10.1007/s11251-013-9282-5.

Loibl, K., \& Rummel, N. (2014b). Knowing what you don't know makes failure productive. Learning and Instruction, 34, 74-85. https://doi. org/10.1016/j.learninstruc.2014.08.004.
Manalo, E., \& Kapur, M. (2018). The role of failure in promoting thinking skills and creativity: New findings and insights about how failure can be beneficial for learning. Thinking Skills and Creativity, 30, 1-6. https://doi.org/10.1016/j.tsc.2018.06.001.

Persky, A. M., \& Robinson, J. D. (2017). Moving from novice to expertise and its implications for instruction. American Journal of Pharmaceutical Education, 81(9), 60-65.

Randle, J. M., \& Stroink, M. L. (2018). The development and initial validation of the paradigm of systems thinking. Systems Research \& Behavior Science, 35(6), 645-657. https://doi.org/10.1002/sres. 2508.

Read, B. L. (2018). Serial interviews: When and why to talk to someone more than once. International Journal of Qualitative Methods, 17(1), 1-10. https://doi.org/10.1177/1609406918783452.

Saldana, J. (2013). The coding manual for qualitative researchers (2nd ed.). New York: Sage.

Sawyer, R. K. (2019). The role of failure in learning how to create in art and design. Thinking Skills \& Creativity, 33, 1-10. https://doi.org/ 10.1016/j.tsc.2018.08.002.

Schifter, C. C., Natarajan, U., Ketelhut, D. J., \& Kirchgessner, A. (2014). Data-driven decision making: Facilitating teacher use of student data to inform classroom instruction. Contemporary Issues in Technology and Teacher Education, 14(4), 419-432.

Stake, R. E. (2000). Case studies. In N. K. Denzin \& Y. S. Lincoln (Eds.), Handbook of qualitative research (2nd ed., pp. 435-454). New York: Sage.

Tawfik, A. A., Rong, H., \& Choi, I. (2015). Failing to learn: Towards a unified design approach for failure-based learning. Educational Technology Research and Development, 63(6), 975-994. https:// doi.org/10.1007/s11423-015-9399-0.

Van Tiem, D., Moseley, J. L., \& Dessinger, J. C. (2012). Fundamentals of performance improvement: Optimizing results through people, process, and organizations (3rd ed.). London: Pfeiffer. https://www. pearson.com/content/dam/one-dot-com/one-dot-com/global/Files/ efficacy-and-research/skills-for-today/Critical-ThinkingFullReport.pdf.

Ventura, M., Lai, E., \& DiCerbo, K. (2017). Skills for today: What we know about teaching and assessing critical thinking. London: Pearson.

Westermann, K., \& Rummel, N. (2012). Delaying instruction: Evidence from a study in a university relearning setting. Instructional Science, 40(4), 673-689. https://doi.org/10.1007/s11251-012-9207-8.

Zhou, C., Chen, H., \& Luo, L. (2014). Students' perceptions of creativity in learning information technology (IT) in project groups. Computers in Human Behavior, 41, 454-463. https://doi.org/10. 1016/j.chb.2014.09.058.

Ziegler, E., \& Kapur, M. (2018). The interplay of creativity, failure and learning in generating algebra problems. Thinking Skills \& Creativity, 30, 64-75. https://doi.org/10.1016/j.tsc.2018.03.009.

Zimmerman, B. J. (1990). Self-regulated learning and academic achievement: An overview. Educational Psychologist, 25(1), 3-17. https:// doi.org/10.1207/s15326985ep2501_2.

Publisher's Note Springer Nature remains neutral with regard to jurisdictional claims in published maps and institutional affiliations. 